\title{
The value of a complex unit for the simultaneous use of a transverse surface and a longitudinal ridge when irrigating cotton
}

\author{
Shukhrat Ostonov ${ }^{1 *}$, Makhbuba Ikramova $^{2}$, and Shavkat Safarov ${ }^{1}$ \\ ${ }^{1}$ Bukhara branch of the Tashkent Institute of Irrigation and Agricultural Mechanization \\ Engineers, Bukhara, Uzbekistan \\ ${ }^{2}$ Scientific Research Institute of Breeding, Seed Production and Agricultural Technology of Cotton \\ Growing, Bukhara Scientific Experimental Station, Bukhara, Uzbekistan
}

\begin{abstract}
The article provides data on the development of a complex Palodelatel unit without damaging growing plants, the simultaneous rate of a transverse surface and a longitudinal ridge in saline, sloping uneven soils in the Bukhara region, also taking into account the slope and unevenness of the soil relief, in a scientifically based form it is stated about the uniform provision of irrigation water and reduction of manual labor, working time, duration and distance between irrigation days, saving spent irrigation water and elimination of salt spots and reducing the cost of irrigation water by $25 \%$, irrigation duration by $1.5-2$ days, crop addition by $5-4.2 \mathrm{c} / \mathrm{ha}$.
\end{abstract}

\section{Introduction}

Over the past 10 years, especially in desert and saline soils (in the Bukhara oasis), global climate change and extreme air temperatures, from the 2 nd decade of May to the 1st decade of autumn, there are hotter and longer hassles, and with a lack of water, for growing high-quality crops has some problems. In connection with the elimination of such problems, "On measures to radically improve the system of land reclamation and rational use of water resources" (October 29, 2007) and in the Action Strategy for 2017-2021 were adopted, the approved decree of the President of the Republic of Uzbekistan states that "... The use of intensive methods of agricultural production, first of all, the introduction of modern water and resource-saving technologies" is one of the most important tasks [1, 2]. In this regard, conducting scientific research to identify the effectiveness and use of water and resource-saving integrated aggregate - simultaneous rates of the transverse surface and longitudinal ridge on saline and uneven fields of agricultural crops for uniform and economical distribution of irrigation water and elimination of saline spots, obtaining high and high-quality cotton yields - raw materials and other crops, cotton complex, is very relevant.

Typically, irrigated agriculture has higher yields than rainfed agriculture because they are provided with water at normal levels during the growing season of crops. Nevertheless, for a uniform and satisfactory supply of crops with irrigation water and mineral nutrition, to obtain a high and highquality yield, subjective factors must be taken into account, such as bias, unevenness, relief, and degree of salinity, depth of occurrence, the mechanical composition of the soil and hydromodular

*Corresponding author: shuhratostonov2@mail.ru 
zoning, preparation of land for irrigation, etc. Considering that several tasks and factors to a certain extent affect the yield and its quality, it is important how to organize irrigation, efficient use of water, and resource-saving innovative technologies in the irrigation system are one of the most pressing issues [9-11].

To obtain a high and high-quality cotton crop, taking into account the state of the variability of the relief of sown lands, the unevenness and salinity of soils, their slope, ameliorative (semihydromorphic, hydromorphic) state, hydromodular zoning, and the location of salty spots, the depth of groundwater, etc. from such cotton lands, they require, with the help of a palletiser, to divide into small and large floors, depending on the slope of the site, and at the same time put a transverse floor and a longitudinal ridge. And to irrigate efficiently

If during the growing season of cotton, before irrigation with the help of PR- 0.5 (pallet separatorleveler), a transverse surface was placed, then the total coverage of the tractor volume of cotton seedlings would be damaged, and most of the cotton seedlings would remain under the soil, which would lead to a decrease in yield.

If installed manually or with a PR- 0.5 unit (palootdel-equalizer), it requires a lot of labor, working time, and fuel; due to the size of the unit, soil agrophysics deteriorates, and the cost of the product also increases. In such unfavorable conditions, freeing workers from manual labor, working time, and at the same time placing the transverse surface and the longitudinal ridge, taking into account the condition of the soil, irrigate cotton without damaging the seedlings is of great importance in irrigated agriculture and is the most relevant, economical, water and resource-saving, and in an efficient way.

\section{Materials and Methods}

During the growing season of cotton, before irrigation, prepare the soil for irrigation, ensure balanced consumption of water and nutrients by the plant, reduce water loss, create the most optimal irrigation system, irrigate in deserts, saline soils, and groundwater at the height of 2-3 $\mathrm{m}$ and the Bukhara branch of the Tashkent the Institute of Irrigation and Agricultural Mechanization Engineers and the Scientific Research Institute of Breeding, Seed Production and Cultivation of Agrotechnology of the Bukhara Scientific Experimental Station in 2018-2020 for the development of water and resourcesaving equipment, on saline soils to obtain a high and high-quality cotton harvest, at the same time, studies were carried out to test the complex unit of the palletiser - longitudinal ridge and transverse floor, and an application for a new complex unit registered for the RUz patent IPA(FAP 2021 0024) $[3,4],[16-28]$.

The field experiment was laid on two contrast lands, differing in hydromodulated zoning and in the type of soil. A 1-field plot was installed in the Bukhara region, Vobkent region, on a farm named "Muzaffar Zainidinov," Republic of Uzbekistan. The depth of groundwater, which in this area is $3 \mathrm{~m}$, the soil is slightly saline, in terms of the mechanical composition of soils, medium (semihydromorphic, VI hydromodular zoning) and 2-experimental field was located in the Bukhara region, Tashkent Institute of Irrigation and Mechanization of Agricultural Engineers of the Bukhara branch, Kagan training field site, studied by comparing the control option with the use of a complex unit, the simultaneous rates of the transverse floor and longitudinal ridge in areas with increased salinity and heavy soil texture (hydromorphic, IX hydromodular zoning ), in the cotton variety Bukhara-8. In both experiments, the options consisted of 2 options, 4 repetitions, and 8 rows in each farm, and the total land area of both fields was 2.5 hectares, a total of 5 hectares. On the first experimental field, the length of the ridges was $70-80 \mathrm{~m}$, and on field 2-100-110 m, transverse floors were formed. The layout of the field experiment for placement on the experimental site is shown in Figures 1-2.

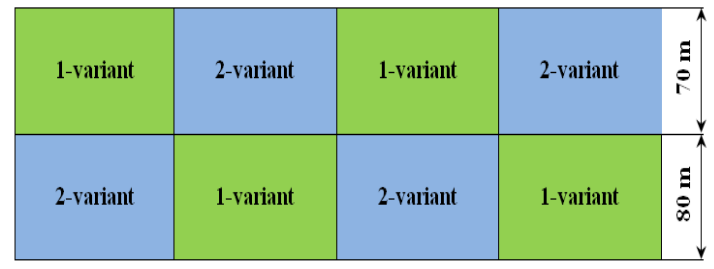

Fig. 1. Experienced floor 


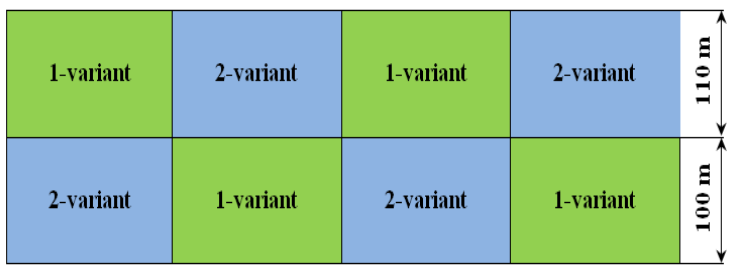

Fig. 2. Experimental field

In both of Ring road s option s in the experimental section placed on randomization method. The studies were carried out following the methodological guidelines adopted in UzNIIX: "Methodology for conducting field experiments" [6] "Methods of the agrochemical, agro physical research in irrigated cotton areas of the field and vegetation experiments with cotton " [7], Methodology of field and vegetation experiments with cotton under irrigation conditions" [8] static data processing was carried out according to B.A. Dospekhov at the "Method of field experiment" [5] and the help of the mathematical-static computer program Microsoft Excel.

Literary review. Uzbekistan has, in general, more than $44797,7 \mathrm{mln}$. hectares of land, of which just 20 million ha is used in agriculture governmental branch, and irrigated lands are compiled 3,2 mln hectares at Kotor's grown every year agricultural products to ensure population. Irrigated land, depending on the ratio of the soil of moisture, falls into automorphic, semihydromorphic, and hydromorphic $[9,13,14,15]$. In the Bukhara region, Society and e op on Shai land is 274612 hectares, of which 38903 hectares (14.2\%) nonsaline, and 235709 hectares $(85,8 \%)$ belong to those minutes or less salinization spine. In the Bukhara region, in accordance with the recommended scale reclamation (semihydromorphic and hydromorphic), zonal areas fall into II, III, IV, V, VI, VII, VIII, IX 10 minute hydromodule areas and in dependence on the power of texture, structure and adding soil s soil in the aeration layer and the depth of ground water $(1,0-2,0 ; 2.0-3.0 \mathrm{~m})$ [9-15].

When watering cotton, depending on the meliorative (semi-hydromorphic and hydromorphic) state of soils and zonal groups of hydromodules, taking into account the growing season, the norms and terms of their irrigation are established. For example, in areas with desert, light loamy, gravel soils, with a groundwater depth of $3 \mathrm{~m}$ (in the II hydromodular zoning ), cotton is watered during the period of growth and development from germination to flowering 3 times, during the flowering period 5 times and during the ripening period - 1 time (3-5-1 system water mode). The interval between waterings is $15-$ 12-15 days; $y$ su sand $\mathrm{x}$ and loamy $\mathrm{x}$, a depth of ground water of $3 \mathrm{~m}$ (III hydromodule area) it is poured cotton 2-4-1 times with intervals of days of watering 16-14-25; sandy and loamy, IV hydromodular region, with a groundwater depth of 2-3 $\mathrm{m}$, also watered according to the 3-5-1 system with an irrigation interval of 12-13-20 days. Areas of the VI hydromodular region with a groundwater depth of 2-3 $\mathrm{m}$ are irrigated according to the 1-41 system with an interval between irrigations of 16-15-25 days; sections of the VI hydromodular region with a groundwater depth of 1-2 $\mathrm{m}$ and of the VII hydromodular region are irrigated according to the 2-5-1 system with an interval between irrigations of 15-12-20 days ; groundwater depth 1-2m in VIII hydromodule area irrigation system 1-3-0 and 1-3-1 intervals irrigation 17-15-25 days and a near them burial it groundwater 1-2 meters in area IX hydromodule in areas with heavy loamy and clayey soils, the irrigation system 1-3-1 with irrigation intervals of 19-16-25 days[9,10,11].

When preparing cotton fields for irrigation, the technological process of floor irrigation is not taken into account at the regional and national levels. Standard technological maps developed by the Uzbek Research Institute of Agriculture for 2016-2020 do not consider 
this technological process. Still, in some climatic zones (different salinity, deserts, semihydromorphic and hydromorphic) in the second and third climatic zones, such as in Bukhara region, in this technological process, there is no possibility to irrigate cotton fields [3].

When irrigating such fields, especially on hydromorphic soils, when the soil is saline, and the soils are poor, and water permeability is high, water does not pass along the ridges, penetrates deep into the soil through capillary holes, merges with groundwater, raises groundwater, and creates secondary salinization.

Furthermore, because cotton fields not saturated water oh and fertilizers do not reach the root system in the upper layer of the soil, particles are formed of brine, slowing the growth and development of cotton, height, and accumulation of nutrients efficiency of photosynthesis and reduced.

The Bukhara branch of the Research Institute of Breeding, Seed Production and Agricultural Technologies for Cotton Growing has developed recommendations for farms for growing medium staple cotton varieties "Bukhara-6", "Bukhara-8" and "Bukhara-102", the value of the floor rate and the requirements for it are given [12].

\section{Results and discussion}

The soil and climatic conditions Bukhara region irrigations during the growing season of cotton are determined depending on the temperature of the air, mechanical soil composition, characteristics, and variety, and reclamation zone, preferably in the period of budding soiling of fertilizers necessary, i.e., at this stage field prepared they are to watering.

Before the first irrigation of cotton, before the preparation of irrigation, the necessary mineral fertilizers (35\% nitrogen, $30 \%$ potassium fertilizers) are applied with hilling along the aisles. At the same time, longitudinal ridges and transverse floors are placed without damaging the plants.

According to the results of studies in 1-2 field experiments with two different ameliorative regional and zonal characteristics of the hydromodule in 2018-2020, cotton in option 2 using a utility model in field experiment 1 with a simultaneous rate of ridges and cross-floor, the total water consumption for the period was $-7300 \mathrm{~m} 3 /$ ha, the duration of irrigation is reduced to 15 hours, the interval between waterings is $13-15-22$ days, manual labor is reduced to 4 hours per 5 hectares; cotton harvest - $45 \mathrm{c} /$ ha; water consumption for obtaining 1 centner of yield is $162.2 \mathrm{~m} 3 / \mathrm{ha}$, which is less than the control water consumption by $42.8 \mathrm{~m} 3 / \mathrm{ha}$. 
Table 1. Influence of the complex aggregate of the simultaneous rate of the longitudinal ridge and transverse floor on soils with different reclamation zones on water consumption and cotton yield (average for 2018-2020)

\begin{tabular}{|c|c|c|c|c|c|c|}
\hline $\begin{array}{l}\text { Experienc } \\
\text { e options }\end{array}$ & $\begin{array}{c}\text { Costs of } \\
\text { water in a } \\
\text { period of } \\
\text { vegetation } \\
\text { and, } \mathrm{m}^{3} / \mathrm{ha}\end{array}$ & $\begin{array}{l}\text { between } \\
\text { irrigation } \\
\text { days, day }\end{array}$ & $\begin{array}{c}\text { Duration } \\
\text { of watering, } \\
\text { hour }\end{array}$ & $\begin{array}{l}\text { fertility } \\
\text { c/ha }\end{array}$ & $\begin{array}{c}\text { water costs } \\
\text { for } \\
\text { obtaining } \\
\text { harvest, } \\
\mathrm{m}^{3} / \text { ha }\end{array}$ & $\begin{array}{c}\text { difference } \\
\text { between the cost } \\
\text { of water to } \\
\text { control yield } \\
\mathrm{m}^{3} / \mathrm{ha}, \pm\end{array}$ \\
\hline \multicolumn{7}{|c|}{$\begin{array}{l}\text { 1- experimental field: slightly saline, according to the mechanical properties of soils, medium weight } \\
\text { ( semihydromorph ), VI hydromodular zoning }\end{array}$} \\
\hline 1. Control & 8200 & $12-13-20$ & 17 & 40.0 & 205.0 & 0.0 \\
\hline $\begin{array}{c}\text { 2. When } \\
\text { integrated } \\
\text { unit is } \\
\text { used }\end{array}$ & 7300 & $13-15-22$ & 15 & 45.0 & 162.2 & 42.8 \\
\hline \multicolumn{7}{|c|}{$\begin{array}{l}\text { 2- experimental field: saline, according to the mechanical property of soils, heavy weight } \\
\text { (hydromorph), IX hydromodular zoning }\end{array}$} \\
\hline 1. Control & 5000 & $19-16-25$ & eighteen & 33.4 & 149.7 & 0.0 \\
\hline $\begin{array}{c}\text { 2. When } \\
\text { integrated } \\
\text { unit is } \\
\text { used }\end{array}$ & 4100 & $20-18-27$ & 17 & 37.6 & 109.0 & 40.7 \\
\hline
\end{tabular}

In the first field experiment on the control variant, when the utility model is not used, these indicators were respectively: $8200 \mathrm{~m} 3 / \mathrm{ha}$; 17 hours; for 12-13-20 days, the yield was $5.0 \mathrm{c} /$ ha less than the experimental one. And in the second field, these figures correspond to the experimental variant 2 , where the utility model is used: $4100 \mathrm{~m} 3 /$ ha; 17 hours; $20-18-27$ days; yield - $37.6 \mathrm{c} / \mathrm{ha}$; water consumption for obtaining 1c. yield - $109.0 \mathrm{~m} 3 / \mathrm{ha}$; the difference in water consumption to control is $40.7 \mathrm{~m} 3 / \mathrm{ha}$.

The utility model is proportional to the unused version; these indicators were respectively: $5000 \mathrm{~m} 3 / \mathrm{ha}$; 18 hours; for $19-16-25$ days; the yield was $33.4 \mathrm{c} / \mathrm{ha}$; water consumption for one harvest center $-149.7 \mathrm{~m} 3 / \mathrm{ha}$.

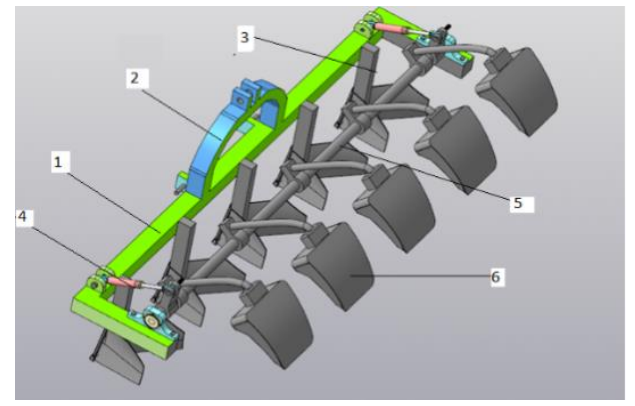

Fig. 3. General view of the complex palletiser unit. 1 is frame, 2 is suspension mechanism, 3 are hillers, 4 are raising and lowering hydraulic cylinders, 5 is a telescopic beam. 6 is bucket-shaped soil-carrying organs 


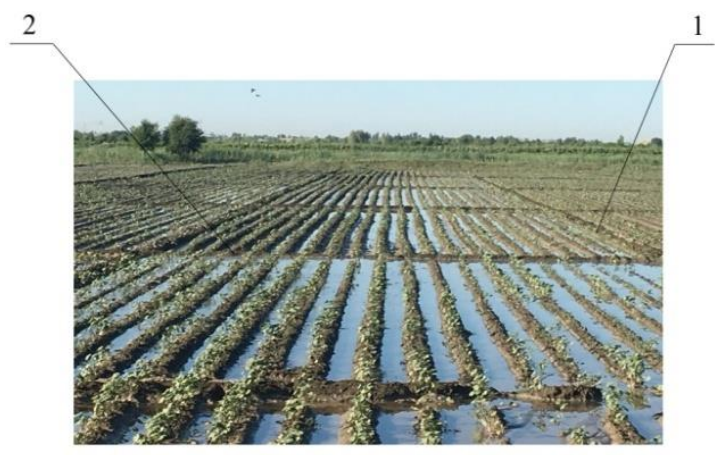

Fig. 4. General view of the floor and in the $n$th portion. 1 is longitudinal ridge; 2 is transverse floor

In this regard, special attention should be paid to ensuring the quantity and quality of the transverse surface and longitudinal ridge in the irrigated fields of the third and some secondary amelioration zones.

Before the first and vegetative irrigation, the formation of transverse surface and after irrigation, the dismantling of the transverse surface and processing between the rows of cotton is also a key task of mechanization.

Before the first and vegetative irrigation, the formation of transverse surface and after irrigation, the dismantling of the transverse surface and processing between the rows of cotton is also a key task of mechanization. In this regard, special attention should be paid to ensuring the quantity and quality of the transverse floor and longitudinal ridge in the irrigated fields of the third and some secondary amelioration zones.

In this regard, special attention should be paid to ensuring the quantity and quality of the transverse floor and longitudinal ridge in the irrigated fields of the third and some secondary amelioration zones.

Before the first and vegetative irrigation, the formation of transverse floors and after irrigation, the dismantling of the transverse floors and processing between the rows of cotton is also a key task of mechanization.

Today these processes are performed entirely by hand. As a result, agronomic processes are not completed in a timely manner, leading to increased labor costs and economic costs.

\section{Conclusions}

As a solution to the problem, scientists of the Bukhara branch of the Tashkent Institute of Irrigation and Agricultural Mechanization Engineers have developed a device for the formation of transverse slabs. Information confirming the novelty of this technical solution has been sent to the Intellectual Property Agency of the Republic of Uzbekistan.

To increase efficiency and reduce fuel consumption, using a complex palletiser unit, you can simultaneously place the transverse surface and the longitudinal ridge in the designated place.

It is aggregated using a suspension mechanism 2 on tractors TTZ 80, T-28X4, MTZ-80. When starting the tractor, the hillers 3 mounted on frame 1 are spud to irrigate the cotton fields between the rows.

As soon as a waterman or a specialist agronomist where the transverse floor was assigned to the indicated place, the tractor driver starts the hydraulic cylinders through the distributor 4. As a result, the bucket-like hillers, hilling the soil, are attached to the movable beam 5 and lower to the ground under the action of the hydraulic cylinders and compacts the soil until it will not rise. 
Once it reaches the set point, the implement is lifted, and the soil is compacted to form a five-row transverse floor. In subsequent transitions, this process is repeated to form a parallel transverse floor. It should be noted that here the tractor driver needs attention and experience because the deviation of the resulting transverse floor from the given line should not exceed $5-10 \mathrm{~cm}$.

In the designated areas along the field's length, the equipment is lowered, and a transverse surface is formed. For example, on cotton field 200 meters long, there should be from three to five transverse fields, taking into account the terrain. As a result of mechanization of the process, labor costs can be halved, and direct costs - up to $25 \%$, irrigation duration by 1.5-2 days, crop addition by 5-4.2 c/ha.

\section{References}

1. Decree of the President of the Republic of Uzbekistan. "On measures to radically improve the land reclamation system and rational use of water resources" October 29, (2007).

2. Decree of the President of the Republic of Uzbekistan. "Action strategies for (20172021.)"

3. Model technological map of cotton growing in Bukhara region for. p. 20. Bukhara, (2019).

4. Ostonov Sh.S. Ways to facilitate the work of farmers. Magazine "Agriculture of Uzbekistan" (4), (2020).

5. B.A. Dospekhov "Method of field experiment" M. 423p. Kolos, (1989).

6. "Methodology of field experience", p.147 Tashkent, (2007).

7. Technique of field and vegetation experiments with cotton under irrigation conditions. p. 126.Tashkent, (1973).

8. Methods of agrochemical, agrophysical research in irrigated cotton areas of field and vegetation experiments with cotton. p. 226. Tashkent, (1981).

9. Shadmanov, D.K., Khasanov M.M., Marufkhanov H.M. Reclamation and hydromodule zoning and irrigation regime for agricultural crops in Uzbekistan. Actual problems of modern science, M .: OOO publishing house "Sputnik +",(5), pp. 74-76. (2020),

10. E.A. Lifshits. A.G. Kim, H. Khakberdiev. Scientifically grounded system of farming in the Bukhara region of the Uzbek SUR. edited by Acad. VASKHNIL A.I. Imamaliev. p. 100.Tashkent, (1984).

11. D.S.Yadgarov, M.L. Ikramova. Scientific-based systems of agriculture in Bukhara region. -p. 165. Bukhara, "Muallif", (2000).

12. Recommendations for the cultivation of agricultural technology "Bukhara varieties of cotton" in the soil and climatic conditions of the Bukhara region. p. 72. Bukhara, "Durdona", (2019).

13. Mukhamadkhan Khamidov, Kamol Khamraev, Shokhrukh Azizov, Gulnora Akhmedjanova. Water saving texnology for leaching salinity of irrigated lands a case study from Bukhara region of Uzbekistan. Journal of critical Reviews. ISSN-23945125. 7. (1). pp. 499-509. (2020).

14. M. Khamidov, K. Khamraev, Water-saving irrigation technologes for cotton in the conditions of global climate change and lack of water resources. CONMECHYDRO (2020). IOP.Rubbishing. IOP. Conf. Series: Materials Science and Engineering 883(2020) 012077.doi 10.1088 /1757-899x/883/012077. pp. 1-10. -(2020)

15. M. Khamidov, K. Khamraev and K. T. Isabaev. Innovative soil teaching technology a case study from Bukhara region of Uzbekistan. 6th International Conference on Agroproducts processing and Farming. IOP Rubbishing IOP.Conf. Series Earth and 
Environmental Science/422 012118 doi 10/1088 / 1755-1315 / 422/1/012118 pp.1-8. (2020)

16. Sh.Ostonov, O. Olimov, А. Zharaev, Kh.Nuriddinov. "Ғуиза ққатор ораларида кўндаланг пол хуосил қилувчи курилма" FAP 202210024 фойдали моделга талабнома.

17. Olimov Kh. Juraev A. Ochilov M .. Methods founding construction and parameters of longitudinal screw pawl-creating device. International Scientific Conference "Construction Mechanics, Hydraulics and Water Resources Engineering" (2020).

18. Olimov Kh. Juraev A. Determining the cross profile of manmade pawl and furrow before creating longitudinal pawl between cotton rows // International Scientific Conference "Construction Mechanics, Hydraulics and Water Resources Engineering" (2020).

19. Khasanov I. S., Khikmatov P. G. and Kuchkarov Zh. Zh. Increasing the stability of work of planning units. Russia Modern materials, equipment and technologies Scientific and practical journal year. pp 221-225. (2016).

20. Kuchqorov J., Musurmanov R. Experience results of softening disc near the grader scoop.International Journal of Advanced Research in Science Engineering and Technology.pp. 10. (2019).

21. I. Khasanov, J Kuchkarov and $\mathrm{H}$ Nuriddinov. Efficiency of irrigated land meliorativity through the usage of fixing softening disk device to base leveler. IOP Conf. Series: Materials Science and Engineering 883 (2020) 012174.

22. Kuchkorov J. J., Musurmanov R. K., Hasanov I. S. The research results of fixing disc device in base land straightener scoop. International Journal of AdvancedResearch in Science Engineering and Technology Vol. and others (2019).

23. M.L. Ikramova, B. N. Rakhmatov. Specific agro-technologies of cotton growing and "Bukhara cotton varieties". Monography, Durdona Publishing House, pp.385. Bukhara, (2020).

24. Rakhmonov S., Umurzakov U., Rakhmonov K., Bozarov I., Karamatov O. Land use and land cover change in Khorezm, Uzbekistan. E3S Web of Conferences, 227, 01002, (2021)

25. Umurzakov U., Mamatov F., Aldoshin N., Mirzaev B. Exploration of tillage technologies in the Republic of Uzbekistan, IOP Conference Series, Earth and Environmental Science, 614(1), 012168, (2020)

26. Umurzakov U., and Djuraev B. Prediction of prices for agricultural products through markov chain model, International Journal of Psychosocial Rehabilitation, 24(3), pp. 293-303, (2020)

27. Umurzakov U., Mirzaev B., Salahodjaev R., Isaeva A., and Tosheva S. Energy consumption and economic growth: Evidence from post-communist countries. International Journal of Energy Economics and Policy, 10(6), pp. 59-65, (2020)

28. Kuchkorov J, Musurmanov R. Experience results of softening disc near the grader scoop. International Journal of Advanced Research in Science Engineering and Technology 